\title{
PENGARUH TUJUH KONTAK KONSELING LAKTASI TERHADAP KEJADIAN POSTPARTUMBLUES
}

\author{
Yanik Muyassaroh $^{1)}$, Komariyah $^{2)}$, Aulia Fatmayanti $^{3)}$ \\ yanikmuyass@gmail.com
}

\begin{abstract}
Postpartum blues is an early onset mental disorders on postpartum mothers, who could be bad on the mother and her baby. This situation usually arises between the three to ten post childbirth, often after the patients out of the hospital. One of the factors causing postpartum blues i.e. difficulty breast-feeding, which can increase the risk of depression. A variety of therapies that can be used to reduce the incidence of depression post, on the mother, one of them with counseling.

Analyse the influence sevencontact of lactation counselling against postpartum blues.

The design of this research uses quasi eksperiment with nonrandom control group design. The number of samples 20responden, each group of 10 respondents. Data analysis using mann whitney.

There was a difference in the control group and treatment group with $\mathrm{p}$ value : 0000

There are influence of seven contacts lactation counseling against postpartum blues.

Keywords: postpartum blues, seven contact of lactation counseling

1), 2), 3), Dosen Prodi DIII Kebidanan Blora Poltekkes Kemenkes Semarang

Postpartum blues merupakan awal terjadinya gangguan mental pada ibu postpartum, yang nantinya bisa berdampak buruk pada ibu dan bayinya. Postpartum blues atau sering juga disebut sebagai maternity blues adalah suatu sindroma gangguan mental ringan yang sering tampak dalam seminggu pertama setelah persalinan dan ditandai dengan gejalagejala seperti reaksi depresi, sedih, disforia, menangis, mudah tersinggung (iritabilitas), cemas, labilitas perasaan, gangguan tidur dan gangguan nafsu makan (Marshall, 2004).

Angka kejadian postpartum blues cukup tinggi yakni 26\% - 85\%. Dari

beberapa penelitian dijelaskan sebanyak $50 \%$ ibu setelah melahirkan mengalami depresi setelah melahirkan dan hampir $80 \%$ ibu baru atu primipara mengalami perasaan sedih setelah melahirkan. Sedangkan di Indonesia angkanya berkisar $50 \%$ - $70 \%$ dan hal ini dapat berlanjut menjadi depresi postpartum dengan jumlah bervariasi dari 5\% hingga lebih dari 25\% (Bobak, et al 2005).

Penyebab postpartum blues masih belum bisa diketahui secara pasti. Namun, ada beberapa faktor yang diperkirakan memicu terjadinya postpartum blues. Beck (2006), melalui studi meta analisisnya memaparkan
\end{abstract}


beberapa variabel prediktor yang dapat menimbulkan postpartum blues. Prediktor tersebut antara lain depresi pranatal, stres merawat anak (childcare stress), stress kehidupan sehari-hari (stressful life event), dukungan sosial, kecemasan pranatal, keintiman suami istri, riwayat depresi sebelumnya, self esteem, temperamen bayi, single marital status, status sosial ekonomi dan kehamilan yang tidak diinginkan atau tidak terencana.

Menurut Amir, et al (1996) dalam Tacked et al (2007), salah satu faktor yang menyebabkan postpartum blues yaitu kesulitan menyusui, yang dapat meningkatkan risiko depresi. Kesulitan-kesulitan ini termasuk puting nyeri, kele-lahan, dan ibu-ibu yang mengkhawatirkan menyusui. Dalam penelitian yang lain, setelah masalah menyusui teratasi, ibu tidak lagi tertekan atau mengalami depresi. Hampir semua studi mengaitkan durasi menyusui dengan depresi postpartum. Postpartum depression memprediksi dan dipre-diksi oleh penghentian proses menyusui dalam beberapa penelitian. Durasi menyusui yang lebih pendek bisa meningkatkan gejala depresi selama postpartum (Dias dan Figueiredo, 2015).

Menurut Groër, et al (2002) menyusui bisa melindungi kesehatan mental ibu, mengurangi stres dan menimbulkan kete-nangan. Para peneliti juga menemukan bahwa menyusui bisa menurunkan mood negatif (Mezza cappa dan Katkin, 2002). Menyusui juga menganugerahkan banyak manfaat kesehatan untuk ibu dan bayi, sementara depresi akan memberikan pengaruh negatif bagi ibu dan bayi (Bogen et al, 2010).

Menurut penelitian yang dilakukan oleh (Zubaran dan Foresti, 2013) menunjukkan bahwa ibu yang menderita gejala depresi mungkin mengalami kurang percaya diri dalam kemampuan mereka untuk menyusui. Dilakukannya 7 kontak konseling laktasi sejak awal yaitu sejak kandungan ibu berusia 28 minggu diharapkan nanti setelah melahirkan tidak terjadi kesulitan untuk menyusui yang bisa memicu terjadinya postpartumblues.

Berdasarkan hasil penelitian Wijayanti, et al (2013) di Kabupaten Blora menun-jukkan bahwa 48,6\% dari ibu postpartum mengalami baby blues syndrome. Oleh sebab itu peneliti ingin mengambil judul pengaruh tujuh kontak konseling laktasi terhadap kejadian postpartum blues di Puskesmas Blora Kota.

\section{METODE}

Desain penelitian ini menggunakan quasi eksperiment dengan rancangan non random with group control design.

Rancangan penelitian ini sebagai berikut:

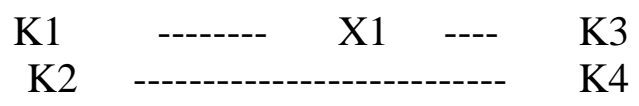

Bagan 3.1: Skema Desain Penelitian

Keterangan :

K1 : Responden kelompok intervensi

K2 : Responden kelompok kontrol

K3,K4 : Pengukuran pada kelompok kontrol dan perlakuan hari ke 10

X1 : Perlakuan tujuh kontak laktasi

\section{HASIL DAN PEMBAHASAN}

Penelitian ini dilaksanakan di wilayah Puskesmas Kota Blora Kabupaten Blora pada bulan Agustus sampai bulan November 2016. Penelitian dilakukan oleh peneliti dengan dibantu oleh bidan dan enumerator. Jumlah responden 
yaitu sebanyak 20 respon-den, 10 untuk kelompok kontrol dan 10 untuk kelompok perlakuan. Dari penelitian tersebut didapatkan hasil penelitian yang disajikan dalam bentuk analisa univariat dan bivariat.

\section{Analisis Univariat}

Karakteristik responden meliputi usia dan pendidikan yang disajikan sebagai berikut:

Tabel 4.1

Karakteristik responden berdasarkan usia

\begin{tabular}{ccc}
\hline Umur & $\begin{array}{c}\text { Kelompok } \\
\text { Kontrol }\end{array}$ & $\begin{array}{c}\text { Kelompok } \\
\text { Perlakuan }\end{array}$ \\
$<20$ & 2 & 0 \\
$20-35$ & 8 & 10 \\
$>35$ & 0 & 0 \\
\hline
\end{tabular}

Tabel 4.1 menunjukkan usia respon den pada kelompok kontrol < 20 tahun sebanyak 2 responden, rentang 20-35 tahun 8 responden dan pada kelompok perlakukan semua responden mempunyai rentang usia $20-35$ tahun.

Tabel 4.2

Karakteristik responden berdasarkan Pendidikan

\begin{tabular}{ccc}
\hline Pendidikan & $\begin{array}{c}\text { Kelompok } \\
\text { Kontrol }\end{array}$ & $\begin{array}{c}\text { Kelompok } \\
\text { Perlakuan }\end{array}$ \\
\hline Dasar & 3 & 0 \\
\hline Menegah & 7 & 10 \\
\hline $\begin{array}{c}\text { Perguruan } \\
\text { Tinggi }\end{array}$ & 0 & 0 \\
\hline
\end{tabular}

Tabel 4.2 menunjukkan pendidikan responden pada kelompok kontrol yang mempunyai pendidikan dasar sebanyak 3 responden, menengah 7 responden dan pada kelompok perlakukan semua responden rmempunyai pendidikan menengah.

\section{Analisis Bivariat}

Analisis bivariat mencakup analisis perbedaan kelompok kontrol dan kelompok perlakuan sebelum dan sesudah pemberian konseling laktasi. Analisis bivariat dalam penelitian ini menggunakan uji wilcoxon untuk masing-masing kelompok dan uji Mann whitney untuk mengetahui perbedaan kelompok kontrol dan kelompok perlakuan dengan level of significance 0,05 data diolah dengan menggunakan software SPSS.

a. Perbedaan pada kelompok kontrol dan kelompok perlakuan

Table 4.5

Perbedaan pada kelompok kontrol dan kelompok perlakuan

\begin{tabular}{lccc}
\hline Kelompok & Jumlah & $\begin{array}{c}\text { Nilai } \\
\text { mean }\end{array}$ & $\begin{array}{c}\text { Uji } \\
\text { Mann } \\
\text { whitney }\end{array}$ \\
\hline Kontrol & 10 & 15.50 & \multirow{2}{*}{0.000} \\
\hline Perlakuan & 10 & 5.50 & \\
\hline
\end{tabular}

Sumber : Data primer, 2016

Pada Tabel 4.5 menunjukkan bahwa hasil uji mann whitney 0.000 artinya ada perbedaaan kelompok kontrol dan kelompok perlakuan.

\section{PEMBAHASAN \\ Karakteristik responden,}

\section{Umur}

Hasil penelitian pada kelompok kontrol berdasarkan usia responden, responden yang mengalami postpartum blues yaitu 3 responden (30\%) dan 7 responden (70\%)tidak mengalami postpartum blues. Penelitian ini sejalan dengan penelitian yang dilakukan Irawati (2014) didapatkan bahwa umur yang mengalami postpartum blues adalah usia $<20$ tahun dan $>35$ tahun, usia tersebut merupakan usia berisiko bagi perempuan untuk melahirkan seorang bayi. Kondisi ini sesuai dengan 
pendapat Bobak (2005), bahwa faktor pencetus terjadinya postpartum blues adalah pada usia remaja atau kurang dari 20 tahun. Hal ini sesuai dengan data BKKBN (2012) yang menyatakan bahwa usia ideal wanita untuk hamil dan melahirkan adalah pada rentang usia 20-35 tahun. sedangkan pada kelompok perlakuan tidak ada yang mengalami postpartum blues.

\section{Pendidikan}

Hasil penelitian pada kelompok kontrol berdasarkan pendidikan responden, 3 respon-den (30\%) berpendidikan SMP dan mengalami postpartum blues. Hasil penelitian ini sejalan dengan penelitian yang disampaikan Irawati (2014) bahwa hasil penelitian berdasarkan tingkat pendidikan terbanyak yang mengala-mi postpartum blues adalah SD - SMP, yaitu 12 responden $(54,5 \%)$. Hasil penelitian ini menunjukkan bahwapendidikan seseorang sangat berpengaruh terhadap pengetahuan dan kesiapan seorangibu dalam menjalani kehamilan dan persalinan. Hal ini sejalan dengan Latipun (2008) yangmengatakan bahwa pendidikan seseorang akan mempe-ngaruhi cara berpikir dan cara pandang-terhadap diri dan lingkungannya karena itu akan berbeda sikap responden yang mempunyaitingkat pendidikan tinggi dibandingkan yang berpendidikan rendah dalam menyikapi prosesselama persalinan.

Perbedaan pada kelompok kontrol dan kelompok perlakuan

Dari hasil penelitian didapatkan bahwa uji beda pada kelompok kontrol dan kelompok perlakuan dengan uji mann whitney didapatkan hasil $\mathrm{p}=$ 0.000 , artinya ada perbedaan .
Hasil penelitian ini sejalan dengan penelitian yang dilakukan oleh (Rusli dkk, 2011) bahwa ibu yang diberikan konseling laktasi atau menyusui pada masa kehamilan akan lebih siap menghadapi peran baru sebagai seorang ibu sehingga bisa mencegah terjadinya postpartum blues.

Pada penelitian (Psychiatry, 2010) menunjukkan bahwa kehamilan adalah waktu yang optimal untuk campur tangan untuk meningkatkan kepercayaan diri ibu dalam mempersiapkan diri menjadi seorang ibu. Dengan pemberian konseling menysui bisa meningkatkan kesehatan emosional. Apabila ibu berhasil dalam proses menyusui, tidak hanya baik untuk tubuh, tetapi juga untuk pikiran. Studi menunjukkan bahwa ibu menyusui kurang menunjukkan kecemasan dan postpartum blues daripada ibu yang memberikan susu formula

Menurut sebuah studi yang dilakukan pada 14.000 ibu baru, menyusui dapat mengurangi risiko postpartumblues. Pene-litian yang diterbitkan dalam jurnal Ke-sehatan ibu dan anak tahun 2014, menghimbau untuk memberikankonseling dan dukungan yang lebih bagi perempuan agar mampu menyusui.

Hal ini menunjukkan bahwa, wanita yang mendapatkan konseling menyusui, mempunyai pengurangan risiko postpartumblues.Tetapi ada peningkatan resiko postpartumblues lebih dari dua kali lipat pada wanita yang ingin menyusui tapi tidak mampu menyusui.

Menyusui dapat membantu ibu untuk mengurangi stres, jadi menyusui dapat mencegah masalah-masalah kesehatan mental yang berkembang. Pada proses menyusui akan menghasilkan hormon oksitosin yang berperan dalam 
proses pengeluaran ASI. Hormon oksitosin itu sendiri bisa menekan munculnya hormon kortisol yang juga bisa memicu terjadinya stress yang bisa mengakibatkan gangguan mental pada ibu pasca melahirkan ( Lisa, 2014).

Konseling menyusui bisa mencegah terja-dinya postpartum blues karena konseling akan membantu para ibu untuk mempersiap-kan kondisi psikologis sehingga bisa menikmati peran merawat bayi dan menjadi seorang ibu.Selain itu, ada beberapa bukti bahwa konseling menyusui bisa melindungi atau membantu dalam pemulihan yang lebih cepat dari gejala postpartum blues.

Konseling yang diberikan diantaranya berupa persiapan menyusui. Wanita perlu melakukan sejumlah penyesuaian yang di-perlukan seiring dengan pencapaian peran melalui tahapan yang meliputi $t$ erjadinya kehamilan, proses kehamilan, persalinan, dan pasca persalinan.

Holmes dan Rahe (dalam Kendall \& Hammen, 1998) menjelaskan bahwa meskipun peristiwa-peristiwa tersebut merupakan peristiwa yang umumnya bersifat positif, peristiwa tersebut juga dapat menimbulkan stres karena adanya tuntutan penyesuaian akibat perubahan pola kehidupan. Hal ini terjadi karena kehamilan seorang wanita akan menimbulkan sejumlah konsekuensi berupa tuntutan-tuntutan penyesuaian yang memerlukan respon adaptif.

Hasil penelitian ini sejalan dengan penelitian yang dilakukan oleh Budihastuti dkk (2012), pemberian konseling efektif dalam membantu pembentukan mekanisme koping positif pada ibu sehingga ibu cenderung tidak mengalami postpar-tum blues. Konseling harus dilakukan oleh seorang tenaga kesehatan yang memiliki pengalaman dan kemampuan melakukan konseling sehingga lebih mudah untuk menggali permasalahan yang dialami oleh ibu.

Ibu yang diberikan konseling laktasi cenderung tidak akan menga-lami postpartum blues karena ibu sudah memiliki kesiapan secara psikologis untuk menjadi seorang yang mempunyai peran baru sebagai seorang ibu yang harus merawat dan menyusui anaknya. Pada ibu yang diberikan konseling laktasi sebelumnya maka akan bisa mengatasi kesulitan dalam hal menyusui sehingga ibu cenderung tidak akan menga-lami postpartum blues (Atif, 2013).

\section{SIMPULAN}

Hasil penelitian didapatkan bahwa uji beda pada kelompok kontrol dan kelompok perlakuan dengan uji mann whitney dida-patkan hasil $\mathrm{p}=0.000$, artinya ada perbedaan. Menyusui dapat membantu ibu untuk mengurangi stres, jadi menyusui dapat mencegah masalah masalah kesehatan mental yang berkembang. Pada proses menyusui akan menghasilkan hormon oksitosin yang berperan dalam proses pengeluaran ASI.

\section{SARAN}

1. Bagi peneliti

Hasil penelitian ini dapat dikembangkan untuk penelitian selanjutnya.

2. Bagi responden

Hasil penelitian dapat memberikan pe-ngetahuan terhadap ibu bahwa tujuh kontak konseling laktasi terhadap kejadian postpartum blues, sehingga ibu dapat melakukan 7 kontak konseling laktasi sejak usia kehamilan 28 minggu untuk 
mencegah terjadinya postpartum blues.

3. Bagi pendidikan

Hasil penelitian ini dapat digunakan sebagai pengayaan bahan ajar pada pembe lajaran di kelas oleh dosen kepada maha siswa

4. Bagi pelayanan kesehatan

Hasil penelitian ini dapat memberikan informasi untuk menentukan langkah yang tepat untuk menurunkan angka kejadian postpartum blues.

\section{DAFTAR PUSTAKA}

Amir, L.H., Dennerstein, L., Garland, S.M., Fisher, J., \& Farish, S.J. (1996). Psychological aspects of nipple pain in lactating women. Journal of Psychosomatic Obstetrics \& Gynecology, 17, 53-58.

Beck, C.T. 2006. Postpartum Depression: It Isn't Just The Blues. American Journal

Bobak, Laudermilk, Jensen. 2005. Buku Ajar Keperawatan Maternitas. Jakarta : EGC

Bogen DL, Hanusa BH, Moses-Kolko E, Wisner KL. 2010. Are maternal depression or symptom severity associated with breastfeeding intention or outcomes?. Pubmed. Vol no 8 hal 71-78

Budihastuti,

S.F.,Hakimi,M.,Sunartini,Soejono,

S.K.(2012).Konseling dan

Mekanisme Koping Ibu

Bersalin.Yogyakarta:Journal of

Educational, Health and

Community Psychologi 2012

Vol.1 No.1
Dias CC dan Figueiredo B. 2015.

Breastfeeding and depression: a systematic review of the literature. Pubmed. Vol no hal 142-154

Fiona Marshall, 2004. Mengatasi

Depresi pasca melahirkan. Jakarta : Arcan

Groër, M.W., Davis, M.W., \& Hemphill, J. 2002. Postpartum stress: Current concepts and the possible protective role of breastfeeding. Journal of Obstetric, Gynelogic, \& Neonatal Nursing, 31, 411-417.

Henshaw, C., Foreman, D.,\&Cox, J. 2003. Postnatal Blues : a Risk Factor for Postnatal Depression. Journal of Psychosomatic Obstetrics and Gynaecology ;25(34):267-72

Indarti, J. (2004). Panduan Kesehatan Wanita. Jakarta : Puspa Swara

Kendall-Tackett, K.A. 2007. A new paradigm for depression in new mothers: The central role of inflammation and how breastfeeding and anti-inflammatory treatments protect maternal mental health. International Breastfeeding Journal,

Kenwa, P., Karkata, M.K., Triyani, IGA. 2015. Pengaruh Pemberian Konseling Terhadap Depresi Post Partum Di Puskesmas II Dan IV Denpasar Selatan. Coping Ners Journal. Vol 3 No 2

Masmoudi J, Charfeddine F, Trabelsi S, Feki I, Ben Ayad B, Guermazi M, Baâti I, Jaoua A. Postpartum 
depression: prevalence and risk factors. A prospective Study concerning 302 Tunisian parturients. Tunis Med. 2014 ;92(10): 615-21.

Mezzacappa, E.S., \& Katkin, E.S. 2002. Breastfeeding is associated with reduced perceived stress and negative mood in mothers. Health Psychology,21, 187-193.

Masruroh. 2013. Hubungan Antara

Paritas Ibu Dengan Kejadian

Postpartum Blues. Jurnal

Eduhealth Vol 3 no 2Hal 120-125.

Orshan, S.A. 2008. Maternity, Newborn, and Women's Health Nursing. Philadelphia : Lippincott William\&Wilkins Inc
WHO, 2014. Pelatihan Konseling Menyusui Modul 40 Jam (standar WHO/KEMKES/UNICEF). Jakarta : Perinasia

Wijayanti K, Wijayanti, F.A., Nuryanti, E. 2013. Gambaran Faktor-Faktor Risiko Postpartum blues di Wilayah Kerja Puskesmas Blora. Poltekkes Kemenkes Semarang

Zubaran C dan Foresti K. 2013. The correlation between breastfeeding self-efficacy and maternal postpartum depression in southern Brazil. Pubmed. Vol 4 no 1 hal 915. 